\title{
Efektifitas Sensor Elektrokardiograf (EKG) AD8232 Untuk Mendeteksi Kelelahan Pada Saat Penggunaan SMARTPHONE \\ Teguh Wijaksana Isma ${ }^{1 *}$, Milda Yuliza ${ }^{2}$, Tuti Angraini ${ }^{3}$, Roza Susanti ${ }^{4}$, Effendi $^{5}$ \\ ${ }^{12345}$ Jurusan Teknik Elektro, Politeknik Negeri Padang \\ Jurusan Teknik Elektro Politeknik Negeri Padang, Jl. Limau Manih Padang, 25164, Indonesia \\ *Corresponding Author, email : milda@pnp.ac.id
}

\begin{abstract}
Abstrak - Smartphone merupakan alat elektronik yang banyak digunakan pada era moderen saat ini. Mulai dari anak-anak sampai dengan orang dewasa menggunakan smartphone. Kurangnya pengetahuan dari pengguna smartphone membuat penggunaan smartphone dilakukan secara tidak wajar melebihi dari batas tubuh. Hal tersebut membuat berbagai dampak negatif dari penggunaan smartphone. Misalnya cara untuk dapat mengatasi masalah tersebut adalah dengan cara memanfaatkan sensor Elektrokardiograf (EKG). Penggunaan sensor Elektrokardiograf (EKG) untuk mengetahui kelelahan pengguna smartphone berdasarkan dari irama detak jantung, sensor yang digunakan sebagai deteksi kelelahan adalah tipe AD8232. Hasil dari proses ini adalah aman atau tidak aman pada saat penggunaan smartphone. Ketika BPM bernilai $60<$ BPM $<120$, maka kondisi pengguna smartphone adalah aman, sedangkan ketika BPM $<60$ atau BPM > 120, maka kondisi pengguna smartphone adalah tidak aman. Berdasarkan dari hasil yang telah diuji semakin lama penggunaan smartphone maka nilai BPM akan menjadi semakin berkurang
\end{abstract}

Kata kunci: Elektrokardiograf (EKG), Real Time Clock (RTC), Smartphone, Kelelahan

Abstract - Smartphones are electronic devices that are widely used in the current modern era. Ranging from children to adults are using smartphones. Lack of knowledge from smartphone users makes the use of smartphones improperly exceeding the body's limits. This makes a variety of negative impacts of using a smartphone. One way to overcome this problem is to use an electrocardiograph (ECG) sensor. The use ECG is to determine the fatigue of smartphone users based on heart rate rhythm. The sensor used as fatigue detection is the type AD8232. The result of this process is a secure or insecure condition for using a smartphone. When BPM is worth $60<B P M<120$, the condition of smartphone users is safe, whereas when BPM $<60$ or BPM>120, the condition of smartphone users is unsafe. Based on the results that have been tested, the longer the use of a smartphone, the value of the BPM will sharply be reduced.

Keywords: Electrocardiograph (ECG), Real Time Clock (RTC), Smartphone, Fatigue.

(c) 2020 Elektron Jurnal Ilmiah

\section{PENDAHULUAN}

Smartphone adalah telepon yang memiliki kemampuan seperti komputer, biasanya memiliki layar yang besar dan sistem operasinya mampu menjalankan tujuan aplikasi-aplikasi yang umum (Kamus Oxford Online, 2013). Backer (2010), menyatakan bahwa smartphone adalah telepon yang menyatukan kemampuan-kemampuan terdepan; ini merupakan bentuk kemampuan dari Wireless Mobile Device (WMD) yang dapat berfungsi seperti sebuah komputer dengan menawarkan fitur-fitur seperti Personal Digital Assistant (PDA), akses internet, email, dan Global Positioning System (GPS). Smartphone juga memiliki fungsi lainnya seperti kamera, video, MP3 players, sama seperti telepon biasa. Dengan kata lain, smartphone dapat dikategorikan sebagai mini-komputer yang memiliki banyak fungsi dan penggunanya dapat menggunakannya kapanpun dan dimanapun. [1]

Indonesia adalah "raksasa teknologi digital Asia yang sedang tertidur". Jumlah penduduk Indonesia yang mencapai 250 juta jiwa merupakan pasar yang besar. Pengguna smartphone di Indonesia juga bertumbuh dengan pesat. Lembaga riset digital marketing Emarketer memperkirakan pada 2018 jumlah pengguna aktif smartphone di Indonesia lebih dari 100 juta orang. Dengan jumlah sebesar itu, Indonesia akan menjadi negara dengan pengguna aktif smartphone terbesar keempat di dunia setelah Cina, India, dan Amerika. [2]

Dijey Pratiwi Barakati (2013) dalam jurnal yang berjudul "Dampak Penggunaan Smartphone dalam Pembelajaran Bahasa Inggris", menyimpulkan bahwa dibalik dampak portabilitas terhadap dampak negatif yang dapat membuat ketagihan dalam penggunaan media sosial oleh karena aksesnya yang mudah ke internet, membuat mahasiswa menjadi tidak fokus dalam belajar, tugas mahasiswa tebengkalai, menyontek pada saat ujian berlangsung. [1]

Kezia Oroh, Junita M. Pertiwi, dan Theresia Runtuwene (2016) dalam jurnal yang berjudul "Gambaran Penggunaan Ponsel Pintar Sebagai Faktor Resiko Nyeri Kepala Primer pada Mahasiswa Angkatan 2013 Fakultas Kedokteran Universitas Sam Ratulangi Manado", menyimpulkan bahwa penggunaan ponsel pintar yang terlalu lama karena berbagai fitur yang disediakan menyebabkan kurangnya aktivitas fisik dan adanya keluhan pada mata serta posisi yang salah saat menggunakan ponsel pintar merupakan faktor risiko terjadinya nyeri kepala primer. Jenis nyeri kepala terbanyak ialah tipe tegang sedangkan yang paling sedikit ialah nyeri kepala klaster. [3] 
Berbagai permasalahan di atas adalah hal yang menlatarbelakangi perlu dibuatnya alat ini. Beberapa penelitian yang berkaitan [10][11][12] telah dilakukan sebelumnya, umumnya hanya fokus pada pendeteksian detak jantung Alat ini diharapkan sebagai pemberi peringatan dan mencegah pengguna smartphone yang sudah terlalu lama atau sudah melampauai batas penggunaan, sehingga melindungi para pengguna smartphone dari dampak negatif yang ditimbulkan. Adapun tujuan dari pembuatan alat ini adalah dapat membantu mengurangi resiko dampak negatif yang ditimbulkan dari penggunaan smartphone.

\section{METODE}

\section{A. Rentang Nilai Denyut Jantung Berdasarkan Usia}

Rentang usia detak jantung yang digunakan adalah metode heskell dan fox. Formula ini dirancang oleh Dr. William Haskell dan Dr. Samuel Fox pada tahun 1970. Penelitian yang dilakukan oleh Dr. William Heskell dan Dr. Samuel Fox berdasarkan dari pengamatan sekitar 11 referensi yang terdiri dari penelitian yang diterbitkan atau tidak dipublikasikan. Formula ini mulai banyak digunakan oleh Polar Electro di monitor detak jantungnya.[9]

Rentang Nilai detak jantung dapat dilihat pada tabel 1 dibawah ini:

Tabel 1. Rentang Nilai Detak Jantung Berdasarkan Usia

\begin{tabular}{cccc}
\hline $\begin{array}{c}\text { Umur } \\
\text { (Tahun) }\end{array}$ & $\begin{array}{c}\text { Beat Per } \\
\text { Minute } \\
(\mathbf{B P M})\end{array}$ & Keterangan & Kondisi \\
\hline$<20$ & $60-120$ & Aman & Aktivitas Sedang \\
\hline $20-25$ & $60-117$ & Aman & Aktivitas Sedang \\
\hline $26-30$ & $60-114$ & Aman & Aktivitas Sedang \\
\hline $31-35$ & $60-111$ & Aman & Aktivitas Sedang \\
\hline $36-40$ & $60-108$ & Aman & Aktivitas Sedang \\
\hline $41-45$ & $60-105$ & Aman & Aktivitas Sedang \\
\hline $46-50$ & $60-102$ & Aman & Aktivitas Sedang \\
\hline $51-55$ & $60-99$ & Aman & Aktivitas Sedang \\
\hline $55-65$ & $60-93$ & Aman & Aktivitas Sedang \\
\hline$>75$ & $60-90$ & Aman & Aktivitas Sedang \\
\hline
\end{tabular}

\section{B. Elektrokardiograf (EKG)}

Electrokardiograf (EKG) merupakan suatu gambaran yang terbentuk sebagai hasil dari aktivitas listrik jantung. EKG diambil dengan memasang elektroda pada titik tertentu tubuh pasien. Sinyal Elektrokardiograf mempunyai bentuk spesifik sehingga dapat dijadikan sebagai acuan untuk menentukan kondisi kesehatan jantung oleh ahli jantung. Sinyal EKG direkam menggunakan perangkat Elektrokardiograf. [4]

Elektrokardiogram (EKG) atau electrocardiogram (ECG) adalah suatu grafik yang dihasilkan oleh alat Elektrokardiograf untuk mendeteksi kelainan jantung dengan mengukur aktivitas listrik yang dihasilkan oleh jantung, sebagaimana jantung berkontraksi. EKG dapat membantu mendiagnosis berbagai kondisi kesehatan jantung. [7]

Urutan terjadinya sinyal Elektrokardiograf sebagai berikut:

A. Vektor depolarisasi (terjadi perubahan muatan listrik ) kontraksi atrium dari sinus atrialis ke nodulus atrio ventricularis saat terjadi, menimbulkan gelombang $\mathrm{P}$.

B. Gelombang $\mathrm{R}$ tanda akhir dari kontraksi atria dan awal dari kontraksi ventrikel.

C. Vektor yang timbul karena depolarisasi ventrikel membangkitkan QRS kompleks.

D. Vektor menimbulkan gelombang $\mathrm{T}$ disebabkan repolarisasi ventrikel.

E. Interval P-R adalah menandakan waktu dari permulaan kontraksi atrial sampai permulaan kontraksi ventrikel

F. Interval R-T menunjukkan kontraksi otot (ventricel systole), dan interval T-R menunjukkan adanya relaksasi otot (ventricel diastole). [4]

Bentuk dari sensor Elektrokardiograf (EKG) dapat dilihat pada gambar 1 berikut ini :

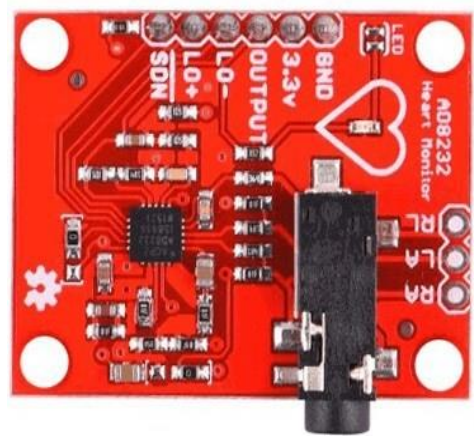

Gambar 1. Elektrokardiograf (EKG) AD8232 [4]

\section{Pengukuran Sinyal Elektrokardiograf (EKG)}

Sinyal Elektrokardiograf (EKG) dapat dilihat pada gambar 2 berikut ini :

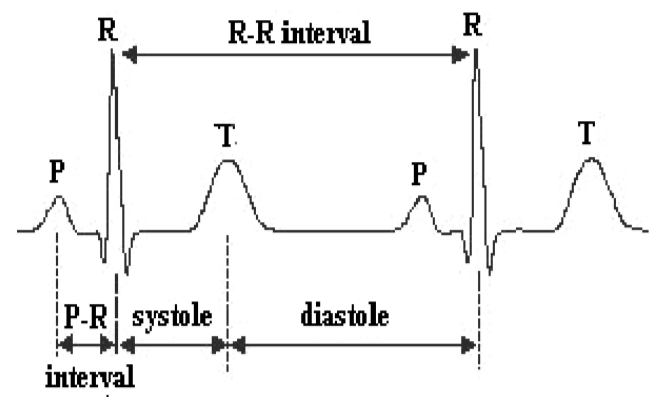

Gambar 2. Sinyal Elektrokardiograf (EKG) [5]

Nilai heartbeat dapat diperoleh dengan menghitung 60 dibagi dengan waktu interval R-R.

$$
B P M=\frac{60}{\text { Interval } R-R}
$$

Nilai heartbeat diperoleh dalam satuan Beat Per Minute (BPM). Aritmia dapat ditentukan dengan menggunakan parameter interval R-R. Apabila interval R-R tidak konsisten maka jantung tersebut bisa mengalami aritmia. [5]

\section{Posisi Peletakan Elektroda}

Dalam transmisi sinyal auskultasi, komponen terpenting adalah data yang diambil dari auskultasi jantung. 
Maka tahapan yang pertama dilakukan adalah mengambil data auskultasi dengan meletakkan sensor pada pergelengan kedua tangan dan pergelangan kaki kiri. Posisi jantung manusia adalah pada tulang iga manusia ke 6 di sebelah kiri dada manusia, atau $5 \mathrm{~cm}$ diatas ulu hati di sebelah kiri. Peletakan sensor sangat berpengaruh, karena apabila sensor tidak diletakkan pada bagian yang tepat maka data yang akan diterima berupa data noise. [6] berikut ini:

Posisi peletakan sensor dilihat pada gambar 3

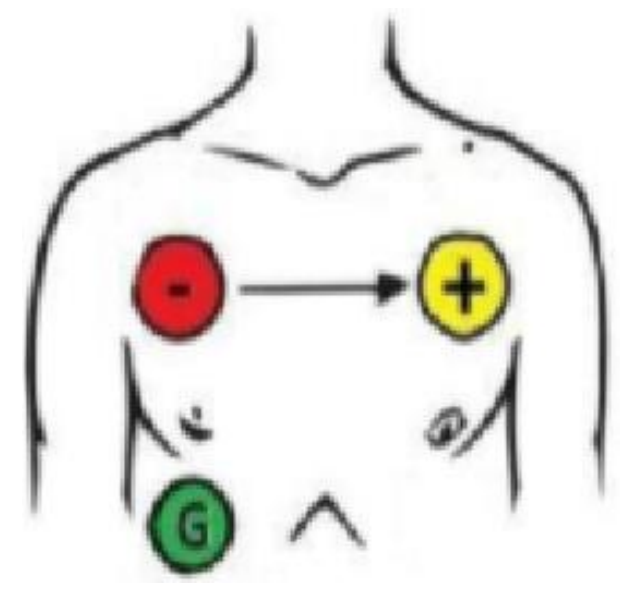

Gambar 3. Letak Posisi Penempatan Elektroda[6]

\section{E. Blok Diagram Secara Umum}

Dalam perancangan alat proteksi efek pengguna smartphone berbasis sensor Elektrokardiograf AD8232 dimulai dari blok diagram yang memberikan gambaran kerja alat secara menyeluruh. Adapun blok diagram dari alat yang akan dibuat dapat dilihat pada gambar 4 berikut ini :

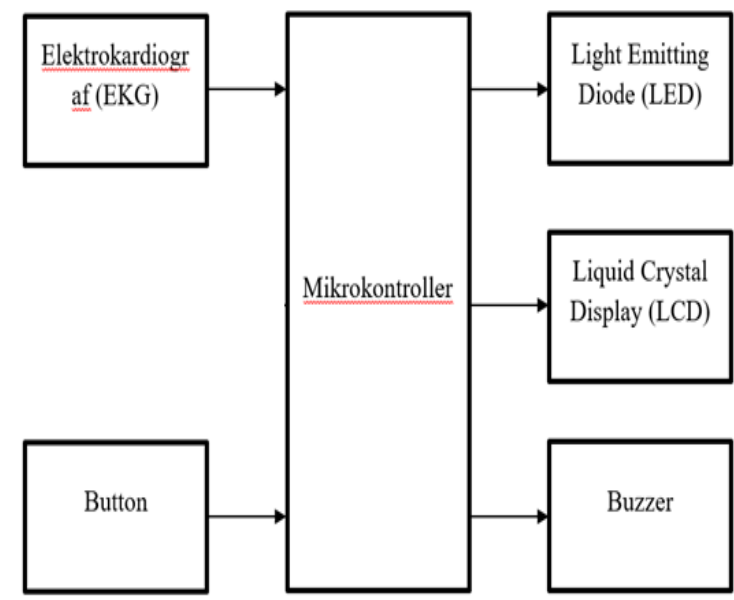

Gambar 4. Blok Diagram Alat

\section{F. Flowchart Deteksi Kelelahan Menggunakan Sensor Elektrokardiograf (EKG) AD8232}

Flowchart merupakan cara bagaimana sebuah alat bekerja. alat ini sendiri bekerja dengan input sensor elektrokardiograf (EKG). System sendiri nantinya akan mengkonversi data yang didapatkan dari sensor menjadi nilai Beat Per Minute (BPM). Tampilan output adalah
LED dan LCD. Flowchart dapat dilihat pada gambar 5 dibawah ini:

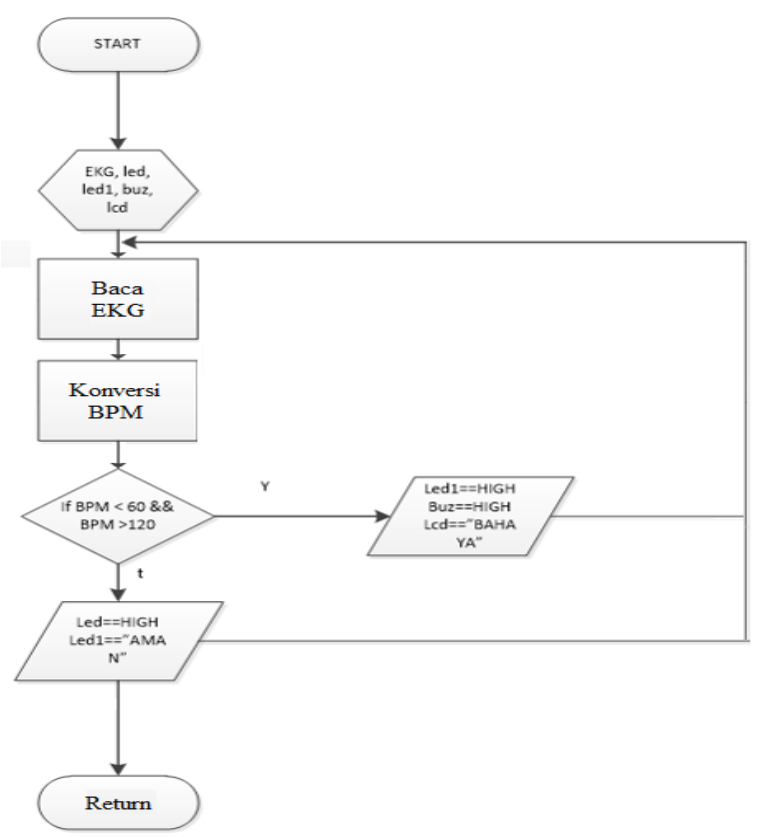

Gambar 5. Flowchart Alat

\section{HASIL DAN PEMBAHASAN}

Pengujian dengan Membandingkan Nilai yang Terukur pada Sensor dengan Nilai yang Dihitung pada Osiloskop

Pengujian dilakukan di Labor Pemograman, Gedung G, Politeknik Negeri Padang. Pengujian dilakukan pada hari jumat tanggal 10 Agustus 2019. Alat yang digunakan pada pengujian ini adalah Osiloskop. Pengujian ini bertujuan untuk membandingkan nilai yang terukur pada sensor dengan nilai yang dihitung berdasarkan gelombang pada osiloskop. Pengujian dilakukan sebanyak 5x. Pengujian nilai BPM dilakukan secara bersamaan. Hasil pengujian dapat dilihat pada tabel 3 dibawah ini:

Tabel 3. Perbandingan Nilai BPM yang Terukur dengan Nilai BPM yang Dihitung

\begin{tabular}{cccc}
\hline No. & $\begin{array}{c}\text { Nil. } \\
\text { Terukur }\end{array}$ & Nil Dihitung & $\begin{array}{c}\text { Persen } \\
\text { Error }\end{array}$ \\
\hline 1 & 74 & 75 & 1,33 \\
\hline 2 & 66 & 66 & 0 \\
\hline 3 & 116 & 109 & 6,42 \\
\hline 4 & 107 & 109 & 1,83 \\
\hline 5 & 107 & 109 & 1,83 \\
\hline \multicolumn{4}{c}{ Rata-Rata Persen Error } \\
\hline
\end{tabular}

Berdasarkan tabel 3, dapat dilihat dari 5x percobaan yang telah dilakukan nilai persentase error terbesar yaitu pada percobaan ke 3 dengan nilai persentase error 6,42, sedangkan nilai persentase error terkecil yaitu pada percobaan kedua yaitu 0 . Nilai rata-rata persentase error berdasarkan tabel adalah 2,822. Berdasarkan tabel, semakin tinggi nilai Beat Per Minute (BPM) maka nilai frekuensi juga semakin besar. Sedangkan semakin tinggi nilai Beat Per Minute (BPM) maka nilai perioda akan semakin mengecil. 
Tampilan nilai Beat Per Minute pada LCD dapat dilihat pada gambar 6 berikut ini:

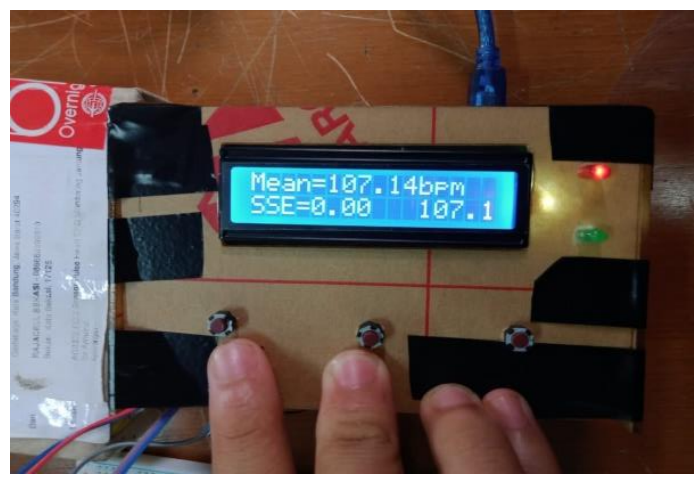

Gambar 6. Tampilan Nilai Beat Per Minute Pada LCD

Sedangkan untuk tampilan gelombang Elektrokardiograf (EKG) pada osiloskop dapat dilihat pada gambar 7 berikut ini:

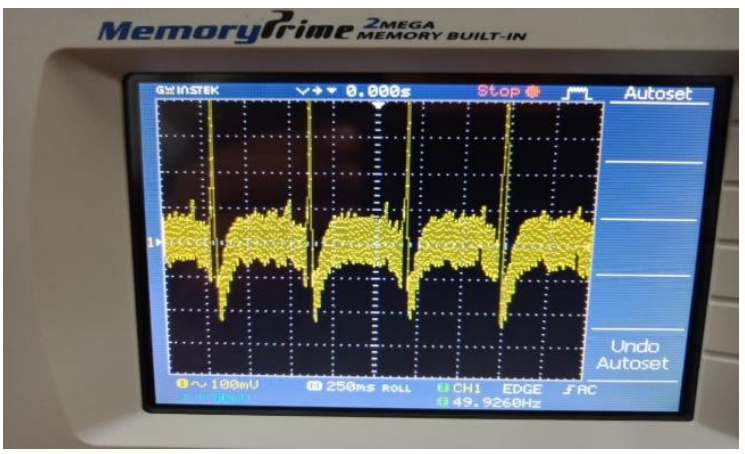

Gambar 7. Tampilan Gelombang Elektrokardiograf Pada Osiloskop

Skala perioda yang digunakan berdasrkan gambar 7 adalah 250ms, sedangkan untuk skala tegangan yang digunakan adala $100 \mathrm{mV}$. Perioda dapat dihitung dengan rumus:

Perioda $=$ Skala Perioda $\times$ Jarak Dari $R-R$

Dari gambar, jarak dari P - P adalah 2,2 kotak besar. Jadi nilai perioda adalah:

$$
\begin{gathered}
\text { Perioda }=250 m s x 2,2 \\
\text { Perioda }=550 m s=0,55 s
\end{gathered}
$$

Setelah mendapatkan nilai perioda, nilai frekuensi dapat dihitung dengan rumus:

$$
\begin{gathered}
\text { Frekuensi }=\frac{1}{\text { Perioda }} \\
\text { Frekuensi }=\frac{1}{0,55 \mathrm{~s}}=1,82 \mathrm{~Hz}
\end{gathered}
$$

Setelah mendapatkan nilai frekuensi dan perioda, nilai Beat Per Minute (BPM) dapat dihitung dengan rumus:

$$
H R=\frac{60}{\text { Interval } R-R}
$$

$$
\begin{gathered}
H R=\frac{60}{0.55 s} \\
H R=109,09
\end{gathered}
$$

Jadi nilai Beat Per Minute (BPM) berdasarkan tampilan gelombang pada gambar 7 adalah 109. Sedangkan untuk nilai Beat Per Minute (BPM) berdasarkan tampilan pada gambar 6 adalah 107. Untuk nilai persentase error adalah:

$$
\begin{gathered}
\text { Persentase Error }=\frac{\mid \text { Nil.Dihitung-Nil.Terukur } \mid}{\text { Nil. Sebenarnya }} \times 100 \% \\
\text { Persentase Error }=\frac{|109-107|}{100} \times 100 \%
\end{gathered}
$$

Persentase Error $=1,83 \%$

Grafik perbandingan nilai yang terukur dengan nilai yang dihitung melalui gelombang osiloskop dapat dilihat pada gambar 8 berikut ini:

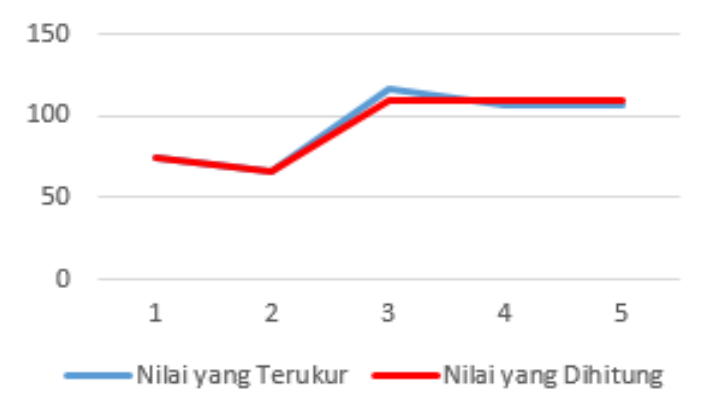

Gambar 8. Grafik Perbandingan Nilai yang Terukur dengan Nilai yang Dihitung

Dapat dilihat grafik pada gambar 9 nilai Beat Per Minute yang terukur dengan Nilai Beat Per Minute yang dihitung tidak terlalu jauh berbeda. Menandakan bahwa sensor Elektrokardiograf (EKG) dapat digunakan sebagai pendeteksi irama jantung (BPM).

\section{Pengujian dengan Membandingkan Lamanya Penggunaan Smartphone dengan Waktu Pengunaan}

Pengujian dilakukan dengan cara mengambil data setiap 30 menit sampai pengguna dinyatakan dalam keadaan lelah. Hasil dapat dilihat pada tabel 4.

Tabel 4. Hasil Perbandingan Lamanya Penggunaan Smartphone dengan BPM

\begin{tabular}{cccc}
\hline No & Waktu & BPM & Ket \\
\hline 1. & 12.54 & 87.98 & Aman \\
\hline 2. & 13.24 & 89.21 & Aman \\
\hline 3. & 13.54 & 80.44 & Aman \\
\hline 4. & 14.24 & 77.90 & Aman \\
\hline 5. & 14.54 & 76.54 & Aman \\
\hline 6. & 15.24 & 68.21 & Aman \\
\hline 7. & 15.54 & 59.32 & Tidak Aman \\
\hline
\end{tabular}


Grafik pengujian dapat dilihat pada gambar 9 dibawah ini:

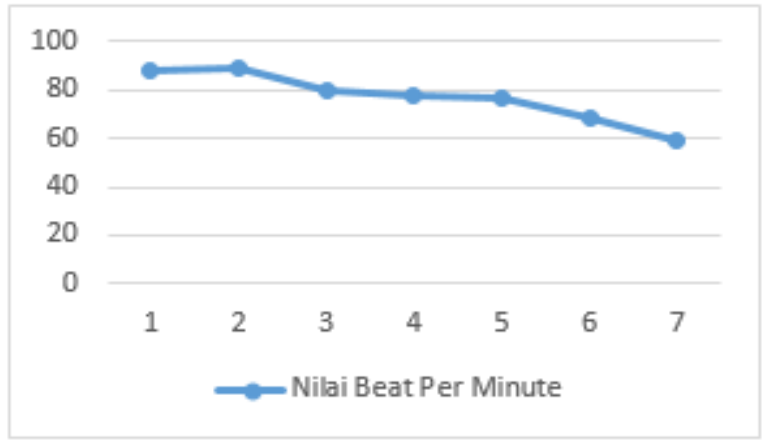

Gambar 9. Grafik Perbandingan Lamanya Penggunaan Smartphone dengan BPM

Berdasarkan dari table dan juga grafik pengaruh antara lamanya penggunaan smartphone dengan nilai BPM adalah semakin lama penggunaan smartphone maka nilai BPM menjadi semakin menurun.

\section{KESIMPULAN}

Sensor Elektrokardiograf (EKG) AD8232 digunakan untuk mendeteksi kelelahan pada saat pemakaian smartphone berdasarkan irama jantung. Nilai error dari sensor Elektrokardiograf dibandingkan dengan alat EKG tipe Philips adalah 2, 282\%. Nilai error dari sensor Elektrokardiograf dibandingkan dengan nilai yang dihitung dari gelombang yang ditampilkan osiloskop adalah $1,83 \%$. Terdapat perubahan kenaikan dan penurunan dari nilai irama detak jantung terhadap lama penggunaan smartphone dengan perubahan sebanyak 5 15 BPM.

\section{REFERENSI}

[1] Barakati, D.P. (2013). Dampak Penggunaan Smartphone dalam pembelajaran Bahasa inggris (persepsi mahasiswa). Jurnal elektronik fakultas sastra universitas sam ratulangi, 1(1).

[2] Indah Ramayani. (2015). Indonesia Raksasa teknologidigitalasia.https://kominfo.go.id/content/detail/6095 lindonesia-raksasa teknologi-digital-asia/0/sorotan_media. (16 Juli 2019).

[3] Oroh, K., Pertiwi, J. M., \& Runtuwene, T. (2016). Gambaran penggunaan ponsel pintar sebagai faktor risiko nyeri kepala primer pada mahasiswa angkatan 2013 Fakultas Kedokteran Universitas Sam Ratulangi Manado. e-CliniC, 4(2). Hal 6.

[4] Purnamasari, R., Hadiyoso, S., Rohmah, Y. S., \& Ramdani, A. Z Perhitungan Denyut Jantung Berdasarkan Sinyal Ekg Berbasis Fpga. Hal 1.

[5] Purwanda, Fendy., Triwiyanto., Welina Ratnayanti K. Rancang Bangun Elektrokardiograf Menggunakan Mikrokontroler Untuk Mendeteksi Ketidaknormalan Jantung. Universitas Airlangga.

[6] Sugiarto, W. R., Jusak, J., \& Puspasari, I. (2016). Rancang Bangun Alat Elektrokardiograf Untuk Visualisasi, Perekaman, Dan Penyimpanan Sinyal Jantung. Journal JCONES, 5(2), 37-45. Hal 40

[7] Suryana, Y., \& Aziz, R. (2018). Sistem Pemonitor Detak Jantung Portable Menggunakan Tiga Sensor Elektroda. Jurnal AlAzhar Indonesia Seri Sains Dan Teknologi, 4(1), 14-17. Hal 15 .
[8] Wahyudi, E., \& Hartati, S. (2017). Case-Based Reasoning untuk Diagnosis Penyakit Jantung. IJCCS (Indonesian Journal of Computing and Cybernetics Systems), 11(1), 1-10. Hal 3

[9] Wikipedia. (2019). Heart rate. https://en.wikipedia.org/wiki/Heart_rate. (18 Juli 2019).

[10] Mohamad Sofie. Klasifikasi Citra Rekaman Sinyal Elektrokardiogram Menggunakan Metode Analisis Tekstur, K-Nn Dan Multilayer Perceptron. Jurnal SIMETRIS, Vol 7 No 1 April 2016

[11] Muhammad Irmansyah, Era Madona, Anggara Nasution. Design And Application Of Portable Heart Rate And Weight Measuring Tool For Premature Baby With Microcontroller Base," International Journal of GEOMATE, Sept., 2019 Vol.17, Issue 61, pp. 195 201

[12] Mohammad Rofi'i. Identifikasi Fibrilasi Atrium Pada Isyarat Elektrokardiogram (EKG) Menggunakan Support Vector Machine (SVM). Jurnal SIMETRIS, Vol. 9 No. 1 April 2018

[13] Yuhefizar, Anggara Nasution, Roni Putra. Alat Monitoring Detak Jantung Untuk Pasien Beresiko Berbasis IoT Memanfaatkan Aplikasi OpenSID berbasis Web. Jurnal Resti (Rekayasa Sistem dan Teknologi Informasi Vol 3 No 2 (2019): Agustus 2019. Hal. 265-270

[14] Bramasta Agnanda Setiawan, Sony Solehudin, Ira Puspasari,Jusak Jusak. Implementasi Pengamanan Transmisi Sinyal EKG (Elektrokardiogram) secara Daring dengan Metode Anonimasi. Jurnal ELKOMIKA Vol 7 No.1 2019 Hal. 85-96

[15] Cinthia Aliwarga, Aloysius Adya Pramudita , Maria Angela Kartawidjaja. Kompresi Sinyal EKG menggunakan Teknik Parameter Extraction. Jurnal ELKOMIKA Vol 7 No.2 2019 Hal. 308-323 